\title{
Anti-proliferative and apoptosis-inducible activity of labdane and abietane diterpenoids from the pulp of Torreya nucifera in HeLa cells
}

\author{
SHI-PING CHEN ${ }^{1 *}$, MEI DONG ${ }^{1,3^{*}}$, KAZUKO KITA $^{1 *}$, QIN-WEN SHI ${ }^{3}$, BING CONG $^{3}$, \\ WEN-ZHI GUO ${ }^{1}$, SHIGERU SUGAYA ${ }^{1}$, KATSUO SUGITA ${ }^{2}$ and NOBUO SUZUKI ${ }^{1}$ \\ ${ }^{1}$ Department of Environmental Biochemistry, Graduate School of Medicine, Chiba University, \\ Chiba 260-8670; ${ }^{2}$ Department of Clinical Medicine, Faculty Education, Chiba University, Chiba 263-8522, \\ Japan; ${ }^{3}$ Department of Forensic Medicine, Hebei Medical University, 050017 Hebei, P.R. China
}

Received February 22, 2010; Accepted May 7, 2010

DOI: $10.3892 / \mathrm{mmr} \_00000315$

\begin{abstract}
Two abietane and one labdane type diterpenoids were isolated from the methanol extracts of Torreya nucifera pulp and investigated for their ability to inhibit the growth of human cancer cells. Among the three compounds, the labdane compound kayadiol was found to have the most effective inhibitory effect against a wide variety of human cancer cells. Using the MTT assay, kayadiol was determined to have an $\mathrm{IC}_{50}$ (50\% inhibition concentration) of $30 \mu \mathrm{M}$ in HeLa cells, and also to exhibit anti-proliferative effects towards six other human cancer cell lines, with $\mathrm{IC}_{50}$ values of 30-50 $\mu \mathrm{M}$. Kayadiol treatment of HeLa cells resulted in a dose-dependent generation of apoptotic events, including DNA laddering $(\leq 100 \mu \mathrm{M})$. Moreover, kayadiol-treated HeLa cells showed activation of caspases-3 and -9 , as well as an increase in the depolarization of mitochondrial membrane potential and the Bax/Bcl-2 ratio. These results indicate that a mitochondriarelated apoptotic pathway is involved in the kayadiol-induced death of HeLa cells. Kayadiol is therefore a promising novel anti-proliferative agent and merits further investigation.
\end{abstract}

\section{Introduction}

Plants are known to contain chemical compounds that inhibit the proliferation of cancer-derived cells in vitro. Numerous attempts have been made to isolate anti-cancer drugs from plants. For example, the diterpene paclitaxel $\left(\mathrm{Taxol}^{\circledR}\right)$ is a

Correspondence to: Dr Nobuo Suzuki or Dr Kazuko Kita, Department of Environmental Biochemistry, Graduate School of Medicine, Chiba University, Inohana 1-8-1, Chuo-ku, Chiba 260-8670, Japan

E-mail: nobuo@faculty.chiba-u.jp or kita@faculty.chiba-u.jp

${ }^{*}$ Contributed equally

Key words: diterpenoid, kayadiol, human cancer cells, antiproliferative effect, apoptosis well-known anti-proliferative agent isolated from Taxus brevifolia $(1,2)$. Various research has been conducted on other diterpenoid species, with the aim of identifying more effective agents for the treatment of cancer (3). We recently isolated a diterpenoid compound, sarcodonin G, from Sarcodon scabrosus, and demonstrated its anti-proliferative activity on human cancer cells (4).

Torreya nucifera is an evergreen coniferous tree that is commonly found in areas of Japan, Korea and China (5). The seeds of this tree exhibit significant insecticidal activity (6), while the fruit is widely used in folk medicine for the treatment of tapeworm infestation (in Korea) and for the induction of abortion (in Japan) (7). To date, analyses of the cell growth inhibition activities of Torreya nucifera have been focused on extracts from its leaves and wood (8), and a number of sesquiterpenoids isolated from the wood oil of the tree were reported to have an inhibitory effect on cell growth (9). However, there have been no reports on diterpenoids isolated from the pulp of the tree, although the pulp may contain numerous intriguing chemical compounds.

In the present study, two abietane diterpenoids, 18-hydroxyferruginol (8, 11, 13-abietatriene-12, 18-diol) (10) and hinokiol (8, 11, 13-abietatriene-3, 12-diol) (11), and a labdane diterpenoid, kayadiol [8(17), 13-labdiene-15,18-diol] (Fig. 1) (12,13), were isolated from the pulp of Torreya nucifera. There is little available information on the biological activity of these isolated chemical compounds; thus, we investigated their inhibitory activity on the growth of cancer cells. Among the three compounds, kayadiol was found to exert the greatest growth inhibition in a wide variety of human cancer cells.

\section{Materials and methods}

Agents. Labdane and abietane diterpenoids were isolated from the air-dried pulp of Torreya nucifera according to previously reported methods (14). Briefly, air-dried pulp (1.3 kg) was extracted with 101 methanol at room temperature. The combined organic extracts were evaporated under reduced pressure. Water (1 11$)$ and then hexane (ll l l were added and the mixture was well agitated, then lipids in the upper hexane 
phase were removed. This step was repeated three times. The aqueous layer was salted out and extracted with methylene chloride, then the combined methylene chloride extract was dried with anhydrous sodium sulfate, filtered and evaporated, yielding a translucent yellow extract. A portion of the methylene chloride extract (31 g) was subjected to normal phase silica gel column chromatography (300-400 mesh; Qingdao Haiyang Chemical Group Corp., Qingdao, P.R. China). Successive stepwise elution with a Petro-EtOAc gradient (10:7-10:2) yielded 40 fractions (fractions 1-40). An aliquot of each fraction was applied to analytical thin layer liquid chromatography (TLC) using pre-coated silica gel F254 glassbacked plates (Qingdao Haiyang Chemical Group Corp.) without activation. The plates were dipped in a solution of $10 \%$ (v/v) $\mathrm{H}_{2} \mathrm{SO}_{4}$ in ethanol, followed by heating on a hot plate for $5 \mathrm{~min}$. The spots of chemical compounds contained in the fraction were visualized under ultraviolet (UV) light (254 and $365 \mathrm{~nm}$ ). The resulting pattern of each fraction from TLC was used to pool the fractions. Each fraction was further purified by high performance liquid chromatography (HPLC) using a Partisil ODS-2 preparative column $(9.4 \times 250 \mathrm{~mm})$ (Whatman International Ltd., Maidstone, UK) eluted with a 50 -min linear gradient of acetonitrile (25-100\%) in water at a flow rate of $3 \mathrm{ml} / \mathrm{min}$. The ODS- 2 column was equipped with a Waters Delta Prep 3000 instrument coupled to a UV 2487 dual $\lambda$ absorbance detector (Waters Corporation, Milford, MA, USA). Fractions 15 and 29 generated 18-hydroxyferruginol [retention time $(\mathrm{Rt})=29.693 \mathrm{~min}$ ] and kayadiol $(\mathrm{Rt}$ $=33.751 \mathrm{~min}$ ), respectively. Fractions 37-40 were combined and purified by preparative TLC and HPLC and generated hinokiol ( $\mathrm{Rt}=31.430 \mathrm{~min})$.

The structures of the labdane and abietane diterpenoid compounds were elucidated on the basis of spectral data (Fig. 1). Each of the isolated compounds was dissolved in dimethyl sulfoxide (DMSO) (Wako Pure Chemical Industry, Osaka, Japan). The characteristics of the isolated chemical compounds have been reported elsewhere (15). Unless specifically stated, the other reagents were purchased from Wako Pure Chemical Industry.

Cells and culture conditions. The following human cell lines were used: HeLa (a cervical cancer cell line) (16), U251-SP (a glioma cell line) (17), HAC-2 (an ovarian carcinoma cell line) (17), T-Tn (a esophageal carcinoma cell line) (18), T-98 (a glioma cell line) (18), HEC-1 (an endometrial adenocarcinoma cell line) (18) and HLE (a hepatoma cell line) (18). Cells were cultured in Eagle's minimal essential medium (EMEM) (Gibco Brl, Grand Island, NY, USA) containing 10\% (v/v) calf serum (Intergen, NY, USA) and antibiotics (100 $\mu \mathrm{g} / \mathrm{ml}$ streptomycin and $100 \mathrm{U} / \mathrm{ml}$ penicillin G) (Meiji Seika, Tokyo, Japan) at $37^{\circ} \mathrm{C}$ in a humidified atmosphere containing $5 \% \mathrm{CO}_{2}$.

Measurement of cell viability. Cell viability was determined by the MTT assay as previously described (19). Briefly, logarithmically proliferating cells were plated onto 96-well plates (Asahi Glass, Tokyo, Japan) $\left(5 \times 10^{3}\right.$ cells/well) with medium containing the test compounds at the indicated doses, followed by culture for 2 days. The activity of mitochondrial succinic dehydrogenase was measured by further incubation of the cells with $0.5 \mathrm{mg} / \mathrm{ml} \mathrm{3-(4,5-dimethylthiazol-2-yl)-2-}$ ,5-diphenyl tetrazolium bromide (MTT) (Sigma, St. Louis, MO, USA) for $4 \mathrm{~h}$, followed by measurement of absorbance at $570 \mathrm{~nm}$ with a reference wavelength of $655 \mathrm{~nm}$. Cell survival was calculated from the absorbance and presented as a percentage of the surviving cells.

Measurement of cell-cycle phase distribution. Cell-cycle phase distributions were measured as previously described (20). Briefly, cells were cultured in 60-mm dishes with the test compounds (up to $100 \mu \mathrm{M}$ ) for $24 \mathrm{~h}$ followed by trypsinization, then washed three times with phosphate-buffered saline (PBS) and fixed in $70 \%$ cold ethanol. After fixation, the cells were suspended in staining solution $[50 \mu \mathrm{g} / \mathrm{ml}$ propidium iodide (PI), $4 \mathrm{mM}$ sodium citrate, $0.5 \mathrm{mg} / \mathrm{ml}$ RNase A and $0.1 \%$ Triton $\mathrm{X}-100]$ for $10 \mathrm{~min}$ on ice. $\mathrm{NaCl}$ was then added to the solution to a final concentration of $0.15 \mathrm{M}$. The stained cell samples were analyzed using a FACScan instrument (Becton Dickinson, NJ, USA). The percentage of cells undergoing apoptosis was measured by calculating sub-G1 fractions using CellQuest software (Becton Dickinson). Cell-cycle phase distribution measurements were repeated in three different cultures.

DNA fragmentation analysis. Apoptotic DNA fragments were detected as previously described (21). Briefly, cells treated with vehicle and the test compounds (up to $100 \mu \mathrm{M}$ ) were cultured for $48 \mathrm{~h}$ and then lysed for $3 \mathrm{~h}$ at $37^{\circ} \mathrm{C}$ in a solution containing $50 \mathrm{mM}$ Tris- $\mathrm{HCl}$ (pH 8.0), 2 mM EDTA, $1 \%$ SDS and $100 \mu \mathrm{g} /$ $\mathrm{ml}$ proteinase $\mathrm{K}$. Following the addition of $1 / 10$ volume of $3 \mathrm{M}$ sodium acetate, nucleotides were extracted with phenol/ chloroform, and then with chloroform alone. High molecular weight DNA was precipitated by the addition of $7 / 10$ volume of 2-propanol followed by centrifugation at $15,000 \mathrm{rpm}$ for $5 \mathrm{sec}$ at room temperature. Low molecular weight DNA was recovered from the supernatant by centrifugation after incubation overnight at $-20^{\circ} \mathrm{C}$, then re-suspended in $10 \mathrm{mM}$ Tris- $\mathrm{HCl}$ (pH 8.0), $1 \mathrm{mM}$ EDTA and $50 \mu \mathrm{g} / \mathrm{ml}$ of DNase-free RNase A, and finally incubated for $3 \mathrm{~h}$ at $37^{\circ} \mathrm{C}$. Samples were applied to $1.5 \%$ agarose gel containing $0.5 \mu \mathrm{g} / \mathrm{ml}$ ethidium bromide and electrophoresed in $90 \mathrm{mM}$ Tris-borate $(\mathrm{pH}$ 8.0) and $2 \mathrm{mM}$ EDTA at $100 \mathrm{~V}$ for $3 \mathrm{~h}$. DNA ladders were photographed under UV illumination.

Immunoblotting analysis. Immunoblotting analysis was carried out as previously described (20). After treatment with the test compounds for the indicated periods, cells were solubilized in 1X SDS sampling buffer. The whole cell lysates were separated by electrophoresis on $12 \%$ (w/v) SDS-PAGE. Active forms of caspase-3 and -9 proteins were detected using rabbit anti-cleaved caspases-3 antibody (2305-PC-020; Trevigen, MD, USA) (1:800 dilution) and mouse anti-human caspase-9 antibody (MAB8301; R\&D, Minneapolis, MN, USA) (1:1,000 dilution), respectively. The latter antibody detects non-cleaved and cleaved caspase-9. Bax and Bcl-2 proteins were detected using mouse anti-Bax monoclonal antibody (Santa Cruz Biotechnology, Santa Cruz, CA, USA) (1:300 dilution) and mouse anti-Bcl-2 monoclonal antibody (Santa Cruz Biotechnology) (1:300 dilution), respectively. The antigen-antibody complexes were detected by anti-rabbit IgG (NA934V; GE, Healthcare, UK) and anti-mouse IgG (NA931V; Amersham Biosciences, Buckinghamshire, UK), followed by 
<smiles>[R3]C1CCC2(C)c3cc(O)c(C(C)C)cc3CCC2([R16])C1(C)C</smiles>

a, b

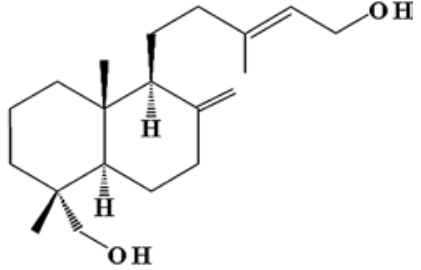

c

\section{a: $\mathbf{R}_{\mathbf{1}}=\mathrm{H} ; \mathrm{R}_{2}=\mathrm{CH}_{3} \mathrm{OH}$ \\ b: $\mathbf{R}_{\mathbf{1}}=\mathbf{O H} ; \mathbf{R}_{2}=\mathbf{C H}_{3}$}

Figure 1. Chemical structures of (a) 18-hydroxyferruginol, (b) hinokiol and (c) kayadiol.

A

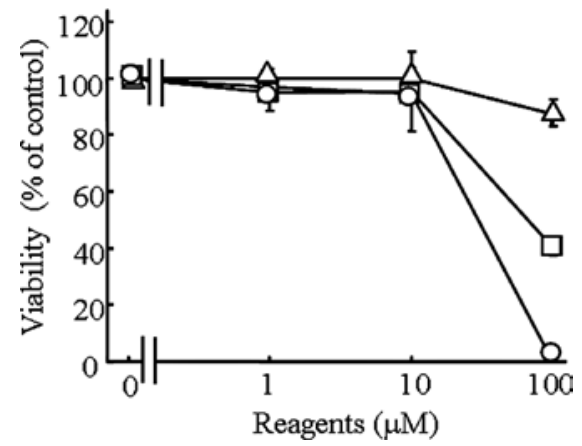

B

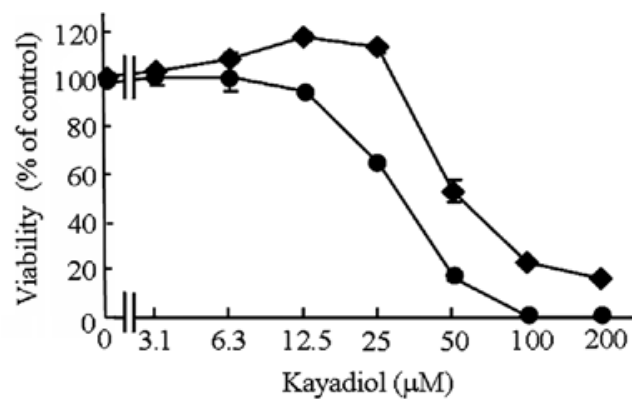

Figure 2. Cell viability as determined by the MTT assay. (A) HeLa cells were treated for 2 days with three diterpenoid compounds: 18-hydroxyferruginol (), hinokiol $(\triangle)$ or kayadiol (O). (B) HeLa $(\bullet)$ and HLE $(\bullet)$ cells were treated for 2 days with kayadiol at the indicated doses. Data are presented as the means $\pm \mathrm{SD}$ of three independent experiments.

visualization using the ECL system (GE). Amounts of actin were also analyzed by mouse anti-actin antibody (Illkirch, France) (1:20,000 dilution) as the loading control. The intensities of the protein signals were quantified using Multi Gauge ver. 2.2 image analyzing software (Fuji Foto Film, Tokyo, Japan) and expressed as the relative value to that of actin.

Measurement of mitochondrial membrane potential. Mitochondrial membrane potential was measured using a florescent probe 5,5',6,6'-tetrachloro-1,1',3,3'-tetraethylbenzimidazol-carbocyanine iodide (JC-1) (Cell Technology Inc., Mountain View, CA, USA) according to the manufacturer's instructions (22). As the membrane is hyperpolarized, JC-1 accumulates as aggregates in the mitochondria and stains red. When the membrane potential is depolarized, JC-1 exists as a monomeric form in the cytosol and stains green.
Table I. Anti-proliferative activity of kayadiol in various cancer cell lines.

\begin{tabular}{lc}
\hline Cell line & $\mathrm{IC}_{50}(\mu \mathrm{M})$ \\
\hline HeLa & 30.0 \\
U251SP & 32.7 \\
HAC-2 & 34.4 \\
T-Tn & 38.2 \\
HEC-1 & 42.2 \\
T-98 & 49.4 \\
HLE & 50.3 \\
\hline
\end{tabular}

Cells were cultured in $60-\mathrm{mm}$ dishes with and without the indicated compounds at the indicated doses for $24 \mathrm{~h}$ followed by trypsinization, then suspended in culture medium containing JC- 1 and incubated at $37^{\circ} \mathrm{C}$ in a $5 \% \mathrm{CO}_{2}$ incubator for $15 \mathrm{~min}$. Thereafter, the cells were washed once with EMEM, and fluorescence was measured by FACScan. The ratio of green fluorescence (FL1) intensity to red fluorescence (FL2) intensity was used to determine the extent of the depolarization of mitochondrial membrane potential.

Statistical analysis. Values are expressed as the means of two or more independent experiments, unless specifically stated otherwise, and were compared to results from a vehicle-treated $(0.1 \%$ DMSO) control. Statistical analysis was performed using the Student's t-test with StatView software (ver. 4.5; Abacus Concepts, Berkeley, CA, USA) as previously described (20).

\section{Results}

Inhibition of HeLa cell viability by kayadiol. The cytotoxic potential of three labdane and abietane diterpenoid compounds (Fig. 1) was determined using the MTT assay after culture of HeLa cells in the presence of the chemical compounds (up to $100 \mu \mathrm{M}$ ) for 2 days. Hinokiol treatment resulted in only a slight decrease in cell viability at $100 \mu \mathrm{M}$ (Fig. 2A). The inhibitory effect of 18-hydroxyferruginol treatment on cell viability was greater than that of hinokiol, while kayadiol treatment inhibited cell viability to the greatest extent (Fig. 2A). In a more precise MTT analysis, kayadiol showed an anti-proliferative effect towards $\mathrm{HeLa}$ and $\mathrm{HLE}$ cells with an $\mathrm{IC}_{50}$ value of 30 and $50.3 \mu \mathrm{M}$, respectively (Fig. $2 \mathrm{~B}$ and Table I). The $\mathrm{IC}_{50}$ values of kayadiol in five other human cancer cell lines ranged between 30 and $50 \mu \mathrm{M}$ (Table I). HeLa cells showed the highest sensitivity to the anti-proliferative effect of kayadiol among all the cancer cell lines tested.

Apoptotic events in kayadiol-treated HeLa cells. Cell cycle distribution in the HeLa cells was examined by flow cytometric analysis after PI staining. Cells treated with 18-hydroxyferruginol (up to $100 \mu \mathrm{M}$ ) for $24 \mathrm{~h}$ showed only a slight increase in the sub-G1 phase cell population (apoptotic fraction) (Fig. 3A). By contrast, a distinct dose-dependent increase in the apoptotic fraction was observed in cells treated with kayadiol (Fig. 3A). These results indicate that apoptosis 
A

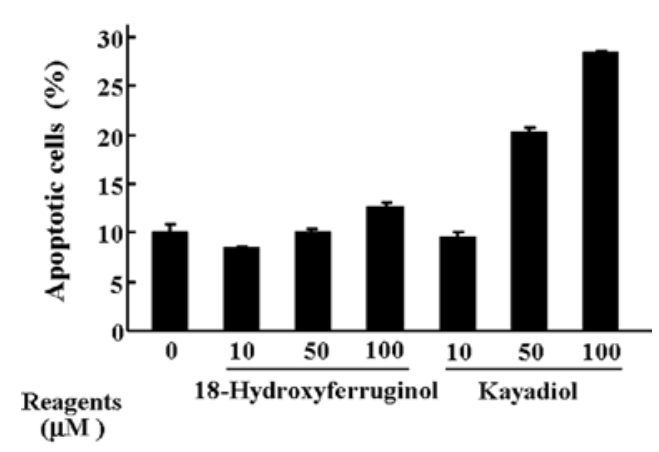

B

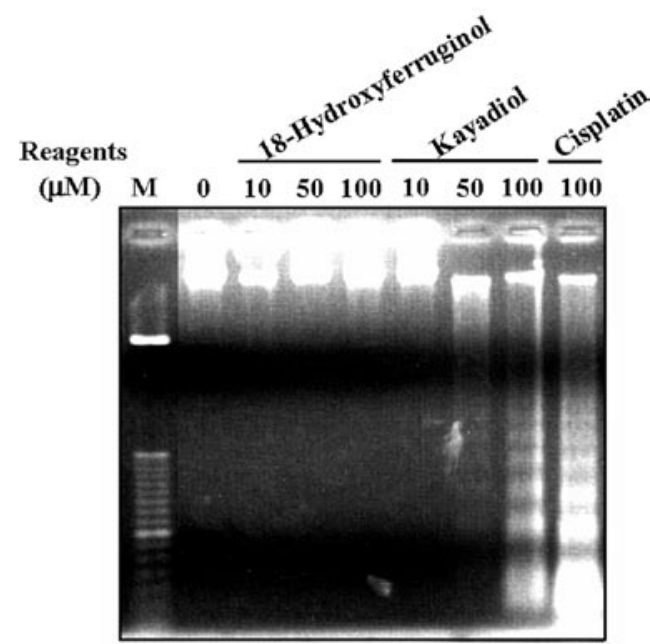

Figure 3. Apoptosis induced by kayadiol in HeLa cells. (A) Flow cytometric analysis of apoptotic population of diterpenoid compound-treated HeLa cells. HeLa cells were treated with 18-hydroxyferruginol and kayadiol for $24 \mathrm{~h}$ and subjected to flow cytometric analysis. At least $1 \times 10^{4}$ cells were counted for each condition and the fraction of sub-G1 population is presented as an apoptotic fraction. Data are presented as means $\pm \mathrm{SD}$ of three independent experiments. (B) DNA fragmentation in diterpenoid compound-treated $\mathrm{HeLa}$ cells. Cells were treated with vehicle (DMSO) at indicated concentrations of 18-hydroxyferruginol and kayadiol and cisplatin for $48 \mathrm{~h}$, and then the total DNA preparation and detection of the DNA fragment were performed as described in Materials and methods. M represents molecular markers.

was induced in kayadiol-treated HeLa cells. To confirm that kayadiol induced apoptosis, the fragmentation status of genomic DNA was examined in HeLa cells treated with the compound. The results were compared to the distinct DNA fragmentation observed in HeLa cells treated with cisplatin $(100 \mu \mathrm{M})$ (Fig. 3B). DNA fragmentation was observed in cells treated with 50 and $100 \mu \mathrm{M}$ of kayadiol (Fig. 3B), but not in cells treated with 18-hydroxyferruginol (up to $100 \mu \mathrm{M}$ ).

Involvement of mitochondria-related pathways in apoptosis in kayadiol-treated HeLa cells. To elucidate the mechanisms of kayadiol-induced apoptosis in the HeLa cells, the possible involvement of the caspases was assessed by detecting the active cleaved forms of caspases-3 and -9. The active form of caspase-3 was detected after $24 \mathrm{~h}$ of treatment with $50 \mu \mathrm{M}$ kayadiol, and was further increased in cells treated with $100 \mu \mathrm{M}$ kayadiol (Fig. 4A). After treatment with 50 and $100 \mu \mathrm{M}$ kayadiol, the amount of active caspase- 9 was also increased, by $\sim 3$-fold in cells treated with $100 \mu \mathrm{M}$ kayadiol as compared to the control (Fig. 4A).
A

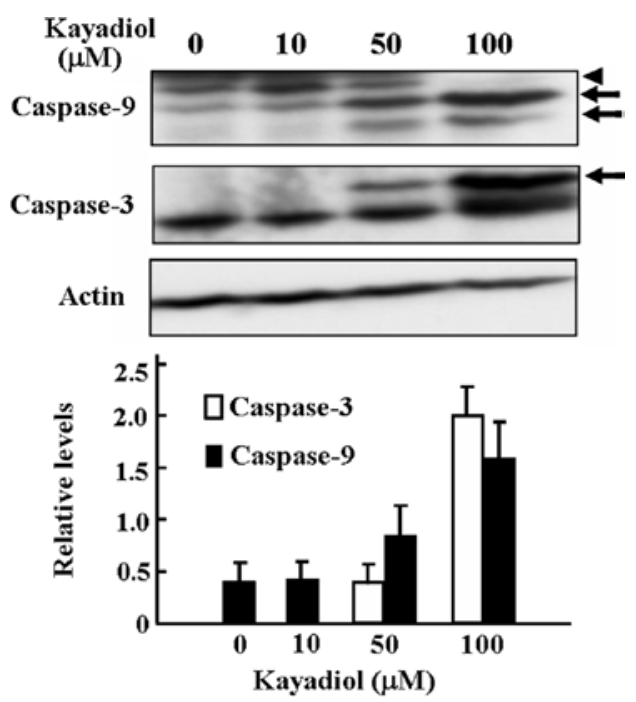

B

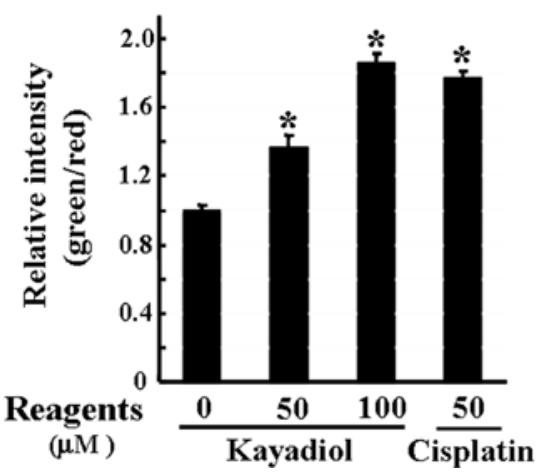

C

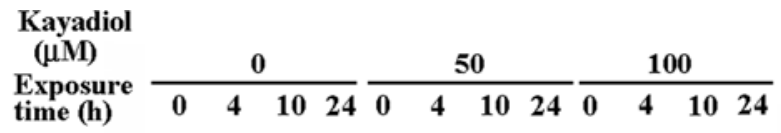

Bcl-2

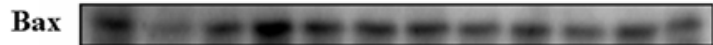

Actin

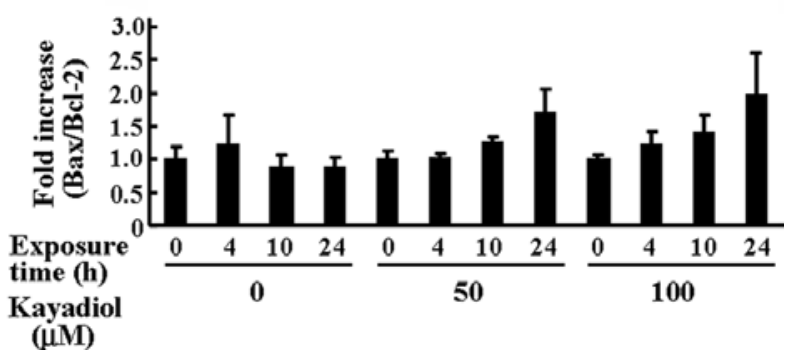

Figure 4. Apoptotic pathway in kayadiol-treated HeLa cells. Cells were treated with vehicle (DMSO) and indicated concentrations of kayadiol or cisplatin for $24 \mathrm{~h}$ and then the expression levels of active forms of caspases-3 and -9 were analyzed by immunoblotting (A), mitochondrial membrane potential was analyzed using JC-1 probe (B) and the expression levels of Bax to Bcl-2 protein were analyzed by immunoblotting (C), as described in Materials and methods. (A) The levels of the cleaved active forms of caspases- 3 and -9 , shown by an arrow, are presented as the expression levels relative to those of actin. The band of the non-cleaved form of caspase-9 is shown by an arrowhead. (B) Reduction of mitochondrial membrane potential is presented as increase in the relative intensity of green fluorescence to red fluorescence. (C) Protein levels of Bax and Bcl-2 were normalized with actin levels and the ratio of Bax to Bcl-2 are presented as relative to those of the cells without kayadiol treatment. Data are presented as means \pm SD. 
The activation of caspase-9 suggested the involvement of a mitochondria-related pathway in kayadiol-induced apoptosis. Thus, mitochondrial membrane potential in HeLa cells was measured using the JC-1 florescent probe. After kayadiol treatment at 50 and $100 \mu \mathrm{M}$, a reduction in membrane potential was observed (Fig. 4B). Treatment with $100 \mu \mathrm{M}$ kayadiol resulted in depolarization to a similar extent as treatment with $50 \mu \mathrm{M}$ cisplatin.

Next, the protein concentrations of Bax and Bcl-2, which are involved in mitochondria-related apoptosis, were measured in HeLa cells treated with and without kayadiol. Western blot analysis showed that the expression of $\mathrm{Bcl}-2$ protein decreased after kayadiol treatment (50-100 $\mu \mathrm{M})$, while the Bax/Bcl-2 protein ratio increased in a time-dependent manner until $24 \mathrm{~h}$ of treatment (Fig. 4C). After $10 \mathrm{~h}$ of treatment with $100 \mu \mathrm{M}$ kayadiol, the ratio was slightly increased, whereas after $24 \mathrm{~h}$ of treatment, it was increased by $\sim 2$-fold.

\section{Discussion}

Of the three chemicals extracted from Torreya nucifera pulp, kayadiol exhibited the greatest inhibition of HeLa cell viability, as determined by the MTT assay (Fig. 2A). The sensitivity of HeLa cells to kayadiol was similar to their sensitivity to another diterpenoid, sarcodonin G (4). The growth inhibition of HeLa cells by kayadiol (Fig. 2) and sarcodonin $\mathrm{G}$ was greater than that induced by $5-\mathrm{FU}$, but weaker than that of cisplatin (4).

Chemotherapeutic anti-cancer agents, including 5-FU and cisplatin, are known to induce apoptosis $(23,24)$. In the present study, this was demonstrated by DNA fragmentation observed in cisplatin-treated HeLa cells (Fig. 3B). Kayadiol (at concentrations in excess of $50 \mu \mathrm{M}$ ) also induced apoptotic events in HeLa cells, as evidenced by an increase in the percentage of cells in the sub-G1 fraction (Fig. 3A), DNA fragmentation (Fig. 3B) and the activation of caspase-3 (Fig. 4A), as well as of caspase-9. Caspase-9 is thought to be activated by an apoptotic signal via mitochondria-dependent mechanisms, and further cleaves and activates the other effector caspases, including caspase-3 $(25,26)$. Here, mitochondrial membrane potential was depolarized in kayadiol-treated HeLa cells (Fig. 4B). Bax and Bcl-2 protein levels were also modulated in the kayadiol-treated HeLa cells (Fig. 4C). Bax and Bcl-2 are pro-and anti-apoptotic proteins, respectively (27). $\mathrm{Up}$-regulation of the $\mathrm{Bax} / \mathrm{Bcl}-2$ ratio suggests the involvement of mitochondrial factors in caspase activation (28-30). In the present study, the Bax/Bcl-2 ratio was increased in HeLa cells treated with kayadiol (at concentrations in excess of $50 \mu \mathrm{M}$ ) (Fig. 4C).

Generally, apoptosis occurs via the mitochondrial (intrinsic) pathway (31) or the death receptor (extrinsic) pathway (32). The mitochondrial (intrinsic) pathway is controlled at the level of the mitochondrial membrane by the Bcl-2 superfamily of proteins. An increase in the expression ratio of the proapoptotic family of proteins vs. the anti-apoptotic family of proteins leads to the disruption of mitochondrial membrane potential and the activation of caspase-9 (25,28-30). Therefore, it is possible that kayadiol treatment (at concentrations in excess of $50 \mu \mathrm{M}$ ) induced the activation of at least the intrinsic mitochondria-related apoptotic pathway in HeLa cells.
The viability of six other human cancer cell lines was decreased by kayadiol treatment. The $\mathrm{IC}_{50}$ values of kayadiol in the other cell lines ranged between 30 and $50 \mu \mathrm{M}$. Thus, kayadiol may have a lethal effect in a wide variety of cancer cells.

From a structure-activity perspective, it would be informative to investigate which functional groups of kayadiol contribute to its substantial anti-proliferative activity. We are now isolating other diterpenoids from various plants, particularly from Taxus mairei (33), and searching for novel diterpenoids that have greater anti-proliferative activity in human cancer cells than kayadiol.

\section{Acknowledgements}

This work was supported in part by grants-in-aid from the Scientific Research Foundation and the Traditional Chinese Medicine Administration Bureau of Hebei (P.R. China), and by the Smoking Research Foundation, Tokyu Foundation for a Better Environment, Hamaguchi Foundation for the Advancement of Biochemistry, Kieikai Research Foundation, Goho Life Science International Foundation, Ministry of Health, Labour and Welfare for the Intractable Diseases Treatment Research Program and the Japan Society for the Promotion of Science (Japan).

\section{References}

1. Fuchs DA and Johnson RK: Cytologic evidence that taxol, an antineoplastic agent from Taxus brevifolia, acts as a mitotic spindle poison. Caner Treat Rep 62: 1219-1222, 1978.

2. McGuire WP, Rowinsky EK, Rosenshein NB, Grumbine FC, Ettinger DS, Armstrong DK and Donehower RC: Taxol: a unique antineoplastic agent with significant activity in advanced ovarian epithelial neoplasms. Ann Int Med 111: 273-279, 1989.

3. Shi Q-W, Dong M, Huo C-H, Su X-H, Li C-F, Zhang X-P, Wang Y-F and Kiyota H: New 14-hydroxy-taxane and 2 $\alpha, 20$ epoxy-11(15 $\rightarrow 1)$ abeotaxane from the needles of taxus canadensis. Biosci Biotechnol Biochem 71: 1777-1780, 2007.

4. Dong M, Chen SP, Kita K, Ichimura Y, Guo WZ, Lu S, Sugaya S, Hiwasa T, Takiguchi M, Mori N, Kashima A, Morimura K, Hirota M and Suzuki N: Anti-proliferative and apoptosis-inducible activity of Sarcodonin G from Sarcodon scabrosus in HeLa cells. Int J Oncol 34: 201-207, 2009.

5. Fukushima I, Sayama Y, Kyogoku K and Murayama H: Isolation of 6-hydroxydehydro abietinol and hinokiol from the leaves of Torreya nucifera Sieb. et Zucc. Agric Biol Chem 32: 1103-1107, 1968.

6. Sakai T, Nishimura K and Hirose Y: Structure and stereochemistry of four new sesquiterpenes isolated from the wood oil of Torreya nucifera. Bull Chem Soc Japan 38: 381-387, 1965.

7. Jang YP, Kim SR and Kim YC: Neuroprotective dibenzylbutyrolactone lignans of Torreya nucifera. Planta Med 67: 470-472, 2001.

8. Sayama Y, Kyogoku K and Murayama H: New diterpenes of Torreya nucifera. Agric Biol Chem 35: 1068-1073, 1971.

9. Kariyone T and Sawaka T: Flavonoids of the leaves of Coniferae and allied plants. I. Flavonoid from the leaves of Torreya nucifera. Yakugaku Zashi 78: 1010-1013, 1958.

10. Harrison LJ and Asakawa Y: 18-Oxoferruginol from the leaf of Torreya nucifera. Phytochemistry 26: 1211-1212, 1987.

11. Shingh M, Pal M and Sharma RP: Biological activity of the labdane diterpenes. Planta Med 65: 2-8, 1999.

12. Zhao Q-S, Tian J, Yue J-M, Chen S-N, Lin Z-W and Sun H-D: Diterpenoids from Isodon flavidus. Phytochemistry 48: 1025-1029, 1998

13. Monacelli B, Pasqua G and Botta B: Abietane diterpene from callus cultures of Taxus baccata. Planta Med 68: 764-766, 2002.

14. Dong M, Zhang M-L, Wang Y-F, Zhang X-P, Li C-F, Shi Q-W, Cong $\mathrm{B}$ and Kiyota $\mathrm{H}$ : Three new taxanes with the 10-alkoxy group from the heartwood of Taxus cuspidate. Biosci Biotechnol Biochem 71: 173-179, 2007. 
15. Cao C-M, Dong M, Zhang M-L, Zhang X-P, Yang Y, Gu Y-C and Shi Q-W: Studies on chemical constitutes of the fruit of Torreya nucifera. Natural Product Research and Development 21: 737-739, 2009

16. Suzuki N and Fuse A: A UV-sensitive human clonal cell line, $\mathrm{RSa}$, which has low repair activity. Mutat Res 84: 133-145, 1981.

17. Suzuki N, Oiwa Y, Sugano I, Inaba N, Sekiya S, Fukazawa I, Yoshida J, Takakubo Y, Isogai E and Saito-Ebihara M: Dipyridamole enhances an anti-proloferative effect of interferon in various types of human tumor cells. Int J Cancer 51: 627-633, 1992.

18. Susuki N, Sekiya S, Sugano I, Kojima T, Yamamori H and Takakubo Y: Dipyridamole combined with tumor necrosis factorenhances inhibition of proliferation in human tumor cell lines. Jpn J Cancer Res 86: 761-769, 1995.

19. Wano C, Kita K, Takahashi S, Sugaya S, Hino M, Hosoya H and Suzuki N: Protective role of HSP27 against UVC-induced cell death in human cells. Exp Cell Res 298: 584-592, 2004.

20. Zhai L, Kita K, Wano C, Wu Y, Sugaya S and Suzuki N: Decreased cell survival and DNA repair capacity after UVC irradiation in association with down-regulation of GRP78/BiP in human RSa cells. Exp Cell Res 305: 244-252, 2005.

21. Wu Y, Kita K and Suzuki N: Involvement of human heat shock protein $90 \alpha$ in nicotine-induced apoptosis. Int J Cancer 100: 37-42, 2002.

22. Cossarizza A, Baccarani-Contri M, Kalashnikova G and Franceschi C: A new method for the cytofluorimetric analysis of mitochondrial membrane potential using the J-aggregate forming lipophilic cation 5,5',6,6'-tetrachloro-1,1',3,3'-tetraethylbenzimidazolcarbocyanine iodide (JC-1). Biochem Biophys Res Commun 30: 40-45, 1993.

23. Lowe SW, Ruley HE, Jacks T and Housman DE: P53-dependent apoptosis modulates the cytotoxicity of anticancer agents. Cell 74: 957-967, 1993
24. Jakubowicz-Gil J, Rzymowska J, Paduch R and Gawron A: The effect of quercetin on pro-apoptotic activity of cisplatin in HeLa cells. Biochem Pharmacol 69: 1343-1350, 2005.

25. Sareen D, van Ginkel PR, Takach JC, Mohiuddin A, Darjatmoko SR, Albert DM and Polans AS: Mitochondria as the primary target of resveratrol-induced apoptosis in human retinoblastoma cells. Invest Ophthalmol Vis Sci 47: 3708-3716, 2006.

26. Schuler M and Green DR: Mechanisms of P53-dependent apoptosis. Biochem Soc Trans 29: 684-688, 2001.

27. Green DR and Kroemer G: The pathophysiology of mitochondrial cell death. Science 305: 626-629, 2004.

28. Luna-More S, Weil B, Bautista D, Garrido E, Florez $\mathrm{P}$ and Martinez C: Bcl-2 protein in normal, hyperplastic and neoplastic breast tissues: a metabolite of the putative stem-cell subpopulation of the mammary gland. Histol Histopathol 19: 457-463, 2004.

29. Lu C-X, Nan K-J, Nie Y-L, Hai Y-N and Min J: Delisheng, a Chinese medicinal compound, exerts anti-proliferative and proapoptotic effects on HepG2 cells through extrinsic and intrinsic pathways. Mol Biol Rep: DOI 10.1007/s11033-009-9930-7, 2009.

30. Wang H-J, Tashiro S, Onodera S and Ikejima T: Inhibition of insulin-like growth factor 1 receptor signaling enhanced silibinin-induced activation of death receptor and mitochondrial apoptotic pathways in human breast cancer MCF-7 cells. J Pharmacol Sci 107: 260-269, 2008

31. Li P, Nijhawan D, Budihardjo I, Srinivasula SM, Ahmad M, Alnemri ES and Wang X: Cytochrome c and dATP-dependent formation of Apaf-1/caspase-9 complex initiates an apoptotic protease cascade. Cell 91: 479-489, 1997.

32. Nagata S: Apoptosis by death factor. Cell 88: 355-365, 1997.

33. Shi Q-W, Zhao Y, Si X, Li Z-P, Yamada T and Kiyota H: 1-Deoxypaclitaxel and abeo-taxoids from the seeds of Taxus mairei. J Nat Prod Res 69: 280-283, 2006. 